See Article page 11.

\section{Commentary: Individualize the strategy of cerebral protection in aortic arch surgery}

\author{
Bo Yang, MD, $\mathrm{PhD}$
}

Cerebral protection is a critical issue in aortic arch surgery, including emergent repair of acute type A aortic dissection (ATAAD) or elective repair of aortic arch aneurysm. Deep hypothermic circulatory arrest (DHCA) allowed us to start performing aortic arch surgery safely. Gradually, cerebral perfusion, including retrograde cerebral perfusion (RCP) and antegrade cerebral perfusion (ACP), was added to the strategy. ACP allowed surgeons to perform DHCA at a much higher body temperature (from $18^{\circ} \mathrm{C}$ to $28^{\circ} \mathrm{C}$ ) with excellent outcomes. Although the outcomes of arch surgery have improved, controversy about the strategy remains, as thoroughly reviewed by Falasa and colleagues. ${ }^{1}$ The main controversies are regarding RCP vs ACP and uni-ACP vs bi-ACP.

In most cases, RCP can be achieved through a separate cannula though the superior vena cava. ${ }^{1}$ Because of the valve in the internal jugular vein, almost $99 \%$ of blood flow from RCP does not reach the brain. This is why DHCA alone can achieve similar results as HCA plus $\mathrm{RCP}$, and $\mathrm{RCP}$ requires patient cooling to $18^{\circ} \mathrm{C}$ (ie, DHCA). ${ }^{1}$ The cooler the patient, the longer the time required for cooling and rewarming, and the greater the risk of more inflammation, coagulopathy, bleeding, and blood transfusion, especially in patients with ATAAD. This is one reason why surgeons are migrating from deep hypothermic to moderate hypothermic circulatory arrest plus ACP for ATAAD repair based on the International registry of aortic dissection ${ }^{2}$ and German Registry of acute

From the Department of Cardiac Surgery, Michigan Medicine, Ann Arbor, Mich. Disclosures: The author reported no conflicts of interest.

The Journal policy requires editors and reviewers to disclose conflicts of interest and to decline handling or reviewing manuscripts for which they may have a conflict of interest. The editors and reviewers of this article have no conflicts of interest.

Received for publication Jan 20, 2021; revisions received Jan 20, 2021; accepted for publication Jan 21, 2021; available ahead of print Jan 27, 2021.

Address for reprints: Bo Yang, MD, PhD, 5155 Frankel Cardiovascular Center, 1500 East Medical Center Dr, Ann Arbor, MI 48109 (E-mail: boya@med.umich.edu). JTCVS Techniques 2021;7:20-1

2666-2507

Copyright (C) 2021 The Authors. Published by Elsevier Inc. on behalf of The American Association for Thoracic Surgery. This is an open access article under the CC BY-NCND license (http://creativecommons.org/licenses/by-nc-nd/4.0/).

https://doi.org/10.1016/j.xjtc.2021.01.026

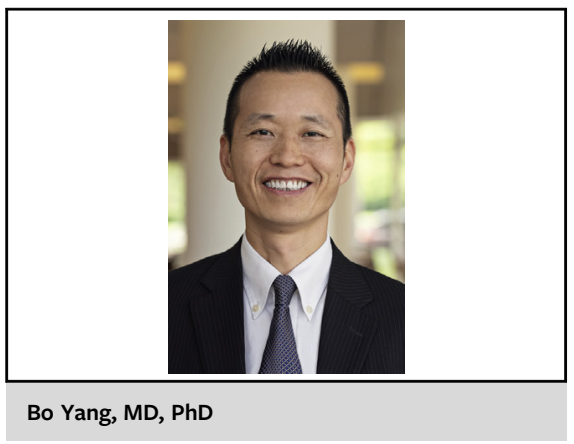

CENTRAL MESSAGE

Surgeons should tailor the strategy of cerebral protection based on the patient's condition, extent of arch repair, and the surgeon's skill set.

aortic dissection type A data. ${ }^{3}$ However, RCP does keep consistent retrograde flow in the arch branch vessels, which could keep debris and air out of the cerebral circulation and prevent embolism.

ACP can be achieved by sewing a Dacron graft (8$10 \mathrm{~mm}$ ) or directly cannulating any arch branch vessels, such as the innominate artery, intrathoracic right subclavian artery, ${ }^{4}$ right axillary artery, left common carotid artery (LCC), right common carotid artery; directly cannulating the ostia of the innominate artery and LCC artery from the open aortic arch; or a combination of both. ACP allows continuous cerebral perfusion throughout HCA with moderate hypothermia; however, the manipulation of arch branch vessels, such as dissecting out and clamping the arch branch vessels or directly cannulating the ostia of the arch branch vessels, could dislodge debris from the vessels or introduce air into the cerebral circulation and cause cerebral embolism. One study showed that patients with ACP had more embolic lesions detected only by magnetic resonance imaging with no clinical symptoms compared with patients with RCP. ${ }^{5}$ The significance of these embolic lesions is unknown, just like patients with mild elevation of troponin but with normal heart function and no clinical symptoms. We also found that with ACP, patients with ATAAD and arch branch vessel dissection had more embolic strokes on the cerebral side of the dissected arch branch vessels. ${ }^{6}$ This finding supports the idea that manipulation of dissected arch branch vessels could cause cerebral embolism. Surgeons should try their best to minimize 
manipulation of the arch branch vessels. One way to minimize manipulation of the arch branch vessels for ACP is to use the right axillary artery for arterial perfusion for cardiopulmonary bypass (CPB). However, that requires a separate incision. Lately, we have been using the intrathoracic right subclavian artery for arterial perfusion with excellent results, ${ }^{3}$ which could be a good choice for CPB and ACP for aortic arch surgery.

There is another advantage of using the healthy arch branch vessel for arterial cannulation for CPB and ACP in patients with a shaggy aortic arch (ie, an aortic arch full of calcification, atheroma, or thrombus). This strategy avoids direct cannulation of the shaggy aorta for cooling with $\mathrm{CPB}$ and dislodging debris from the aortic arch. Because the arterial flow of CPB is from the arch branch vessel to the aortic arch, it prevents the debris, such as calcification, atheroma, or thrombus from being flushed into the brain by CPB before and after aortic arch repair. In those patients with a shaggy aorta, it is also dangerous to directly cannulate the ostia of the arch branch vessels through the arch for ACP, because debris at the ostia could be easily dislodged, causing cerebral stroke.

There is abundant literature to support that uni-ACP is as effective as if not better than bi-ACP, and uni-ACP is recommended for its simplicity. ${ }^{7-9}$ Uni-ACP is usually achieved by sewing a Dacron graft to the innominate artery, intrathoracic right subclavian artery, right axillary artery, or carotid artery. During HCA, the innominate artery and LCC artery are clamped with or without simultaneous clamping of the left subclavian artery. There is little manipulation of the arch branch vessels from inside. Bi-ACP is usually achieved by direct cannulation of both the innominate artery and the LCC artery. Bi-ACP involves significant manipulation of the arch branch vessels from inside. Sometimes the cannula in the innominate artery can be inserted too deep and into the right subclavian artery without perfusing the right common carotid artery artery. If cerebral oxygen saturation decreases significantly $(>30 \%$ of baseline value) unilaterally, then the surgeon should consider converting uni-ACP to bi-ACP or check the position of the cannula in the innominate artery. We use uni-ACP for almost all arch repairs with $<2 \%$ conversion to bi-ACP. ${ }^{9}$ We would plan to use bi-ACP for complex arch reconstruction with an anticipated HCA time longer than 40 minutes, such as a mycotic arch aneurysm requiring extensive arch debridement or total arch with complex distal reconstruction.

One last thing worth mentioning is administration of sedatives, such as phenobarbital, during HCA as an adjunct therapy for cerebral protection. Similar to a study using the German Registry of acute aortic dissection type A data, ${ }^{10}$ we found the sedatives given during HCA increase the postoperative intubation time with no additional cerebral protection. ${ }^{11}$ We have stopped using any additional sedatives for HCA with ACP.

In summary, there are different but equally effective strategies of neuroprotection in aortic arch surgery. Surgeons should be familiar with the pros and cons of each strategy and tailor the strategy for the best outcome for each specific patient based on the patient's specific condition, extent of arch repair, and the surgeon's skill set.

\section{References}

1. Falasa MP, Arnaoutakis GA, Janelle GM, Beaver TM. Neuromonitoring and neuroprotection advances for aortic arch surgery. J Thorac Cardiovasc Surg Tech. 2021;7:11-9.

2. Parikh N, Trimarchi S, Gleason TG, Kamman AV, Ausanio M, Myrmel T, et al. Changes in operative strategy for patients enrolled in the International registry of acute aortic dissection interventional cohort program. J Thorac Cardiovasc Surg. 2017;153:S74-9.

3. Krüger T, Weigang E, Hoffmann I, Blettner M, Aebert H. Cerebral protection during surgery for acute aortic dissection type A: results of the German registry for acute aortic dissection type A (GERAADA). Circulation. 2011;124:434-43.

4. Norton EL, Makkinejad A, Le T, Wu X, Yang B. Intrathoracic right subclavian artery cannulation in aortic arch surgery. J Thorac Cardiovasc Surg Tech. 2020;2:1-5.

5. Leshnower BG, Rangaraju S, Allen JW, Stringer AY, Gleason TG, Chen EP. Deep hypothermia with retrograde cerebral perfusion versus moderate hypothermia with antegrade cerebral perfusion for arch surgery. Ann Thorac Surg. 2019, 107:1104-10.

6. Norton EL, Wu X, Kim KM, Fukuhara S, Patel HJ, Deeb GM, et al. Is hemiarch replacement adequate in acute type $\mathrm{A}$ aortic dissection repair in patients with arch branch vessel dissection without cerebral malperfusion. J Thorac Cardiovasc Surg. December 10, 2020 [Epub ahead of print].

7. Tian DH, Wilson-Smith A, Koo SK, Forrest P, Kiat H, Yan TD. Unilateral versus bilateral antegrade cerebral perfusion: a meta-analysis of comparative studies. Heart Lung Circ. 2019;28:844-9.

8. Preventza O, Simpson KH, Cooley DA, Cornwell L, Bakaeen FG, Omer S, et al. Unilateral versus bilateral cerebral perfusion for acute type A aortic dissection. Ann Thorac Surg. 2015;99:80-7.

9. Norton EL, Wu X, Kim KM, Patel HJ, Deeb GM, Yang B. Unilateral is comparable to bilateral antegrade cerebral perfusion in acute type A aortic dissection repair. J Thorac Cardiovasc Surg. 2020;160:617-25.e5.

10. Krüger T, Hoffmann I, Blettner M, Borger MA, Schlensak C, Weigang E. Intraoperative neuroprotective drugs without beneficial effects? Results of the German registry for acute aortic dissection type A (GERAADA). Eur J Cardiothorac Surg. 2013;44:939-46.

11. Makkinejad AO, Clemence J Jr, Norton EL, Farhat L, Wu XT, Ferman DH, et al. Sedatives during circulatory arrest are not necessary for aortic arch repair in acute type A aortic dissection. Chin Med J (Engl). 2021;134:219-21. 